Article

\title{
Estimation of Parameters Obtained by Electrochemical Impedance Spectroscopy on Systems Containing High Capacities
}

\author{
Zoran Stević $^{1, *}$, Mirjana Rajčić Vujasinović ${ }^{1}$ and Milan Radunović ${ }^{2}$ \\ ${ }^{1}$ University of Belgrade, Technical Faculty in Bor, VJ 12, 19210 Bor, Serbia; \\ E-Mail: mrajcic@tf.bor.ac.rs (M.R.V.) \\ 2 Faculty FUTURA, University Singidunum, Bulevar Mihajla Pupina 12a, 11070 New Belgrade, \\ Serbia; E-Mail: milan.radunovic@encoen.rs (M.R.)
}

* Author to whom correspondence should be addressed; E-Mail: zstevic@tt.bor.ac.rs.

Received: 29 July 2009; in revised form: 3 September 2009 / Accepted: 7 September 2009 / Published: 11 September 2009

\begin{abstract}
Electrochemical systems with high capacities demand devices for electrochemical impedance spectroscopy (EIS) with ultra-low frequencies (in order of $\mathrm{mHz}$ ), that are almost impossible to accomplish with analogue techniques, but this becomes possible by using a computer technique and accompanying digital equipment. Recently, an original software and hardware for electrochemical measurements, intended for electrochemical systems exhibiting high capacities, such as supercapacitors, has been developed. One of the included methods is EIS. In this paper, the method of calculation of circuit parameters from an EIS curve is described. The results of testing on a physical model of an electrochemical system, constructed of known elements (including a $1.6 \mathrm{~F}$ capacitor) in a defined arrangement, proved the validity of the system and the method.
\end{abstract}

Keywords: electrochemical measurements; measurement system; electrochemical impedance spectroscopy; supercapacitors

\section{Introduction}

Every system may be regarded in a frequency domain displaying frequency logarithm on the $\mathrm{X}$-axis and logarithm of module and/or phase angle of transfer function on the $\mathrm{Y}$-axis (Bode plot) [1-3]. For 
the electrochemical system, the transfer function is, in fact, the impedance of an equivalent electrical circuit i.e., its complex form. That is why this method is named electrochemical impedance method (EIS) and it is widely used for characterization of electrochemical systems [4-14]. Applying alternate voltage, $\mathrm{U}(\mathrm{S})$, of different frequencies and constant amplitude to an electrical circuit, responding current, I(S), will appear [2,3]. Amplitude and phase angle of this current will depend on voltage and impedance, $\mathrm{Z}(\mathrm{S})$, of the circuit at that frequency:

$$
\mathrm{I}(\mathrm{S})=\frac{\mathrm{U}(\mathrm{S})}{\mathrm{Z}(\mathrm{S})}
$$

where $S=\sigma+j \omega$ is Laplace complex variable. For sinusoidal excitation the real part $\sigma$ is equal to zero, so the $\mathrm{S}$ becomes $\mathrm{S}=\mathrm{j} \omega$, where frequency, $\omega$, is given in $\mathrm{s}^{-1}$.

Conventional impedance spectra are actually snapshots of transfer functions taken at certain well-defined states of the system (usually stationary, constant potential states). However, for a fuller description of electrochemical systems the evolution of impedance spectra should be investigated during the evolution of the system in both potential and time. With the progress of digital techniques this is becoming increasingly possible [15-17].

The system used for electrochemical measurements consisted of hardware (PC, AD-DA converter NI-621 produced by National Instruments and an analog interface developed at the Technical Faculty in Bor) and software for excitation and measurement (LABVIEW platform and originally developed application software) $[18,19]$. With the goal of achieving a full mathematical analysis of the measured data directly in the LabVIEW application, it was necessary to develop our own mathematical model which is implemented in the measurement software and described in this work. This was not possible with some commercially available fitting software packages (EqCwin, Z-view) [20].

The possibilities of the software described here are compared with the Thales software of the Zahner EIS firm [21,22]. Our model and software are more adequate to the real system because the model better describes real electrochemical systems taking into account the complexity of the processes. The mathematical model developed herein is adapted to the investigated class of electrochemical systems and it is strongly connected with the physical parameters of the system. That approach enabled us to obtain analytical values of mutual relationships between the physical parameters from the system response and, in that way, to make system optimization following some given criteria. This is a significant advantage in compare to the commercial software, where the model is not "visible".

\section{Theoretical Part}

By recording amplitude and phase angle of the response current for every frequency value (excitation voltage known), one can obtain the module and the phase angle of impedance for that frequency; this is presented as one point on the Bode plot which gives the dependence of impedance module, $\mathrm{Z}$, on frequency, $\mathrm{f}$, in logarithmic scale. Logarithm is used in a goal to obtain linear dependences instead of exponential ones. At frequencies obtained by extrapolation of straight segments, some deviation from straight line appears, and the line slope changes gradually. From the heights of the horizontal regions and corner frequencies, one can calculate all the parameters of the circuit of which the Bode plot is recorded, i.e. to estimate the equivalent circuit parameters [23-25]. 
After years of investigating of electrochemical behavior of different electrode materials, different equivalent electrical circuits that exhibit the same response on excitations as considered electrochemical systems have been found [23-26]. One of the most common was the circuit presented in Figure 1.

Figure 1. Considered equivalent electrical circuit.

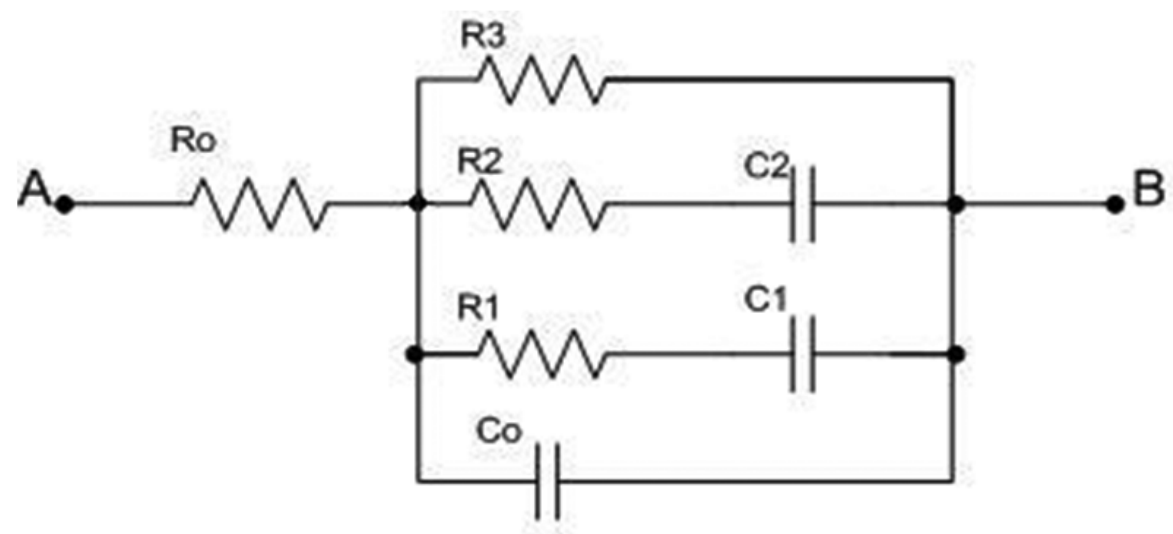

$\mathrm{R}_{0}$ corresponds to the resistance of electrolyte and electrode material, and its value is on an order of magnitude of milliohms $(\mathrm{m} \Omega)$ or Ohms $(\Omega)$. Capacity $\mathrm{C}_{0}$ corresponds to double layer formed on the electrolyte side. Resistances $\mathrm{R}_{1}$ and $\mathrm{R}_{2}$ (order of magnitude ohm to tens Ohms) are related to slow processes of adsorption and diffusion, as well as the capacitances $\mathrm{C}_{1}$ and $\mathrm{C}_{2}$. As a matter of fact, the branch $\mathrm{R}_{1} \mathrm{C}_{1}$ exhibits and describes the inconstancy of parameters in $\mathrm{R}_{2} \mathrm{C}_{2}$ branch. $\mathrm{R}_{3}$ is resistance of self-discharging, meaning that it is reciprocal to leakage current. Its value is on the order of hundreds of Ohms to tens of kiloohms.

For the adopted equivalent circuit (Figure 1) in a general case the impedance equation is complex and not clear enough. So, here a step by step method is applied, one frequency domain after other, knowing the nature of the process, i.e. orders of magnitude of the circuit parameters. For very low frequencies (on the order of $\mu \mathrm{Hz}$ ) all capacitors do not conduct electricity, so the impedance of the circuit remains the serial connection of $\mathrm{R}_{0}$ and $\mathrm{R}_{3}$ :

$$
\mathrm{Z}_{1}=\mathrm{R}_{0}+\mathrm{R}_{3}
$$

where $Z_{1}$ is correlated to the first (the highest) horizontal plateau in Figure 5. At frequencies on the order of $\mathrm{mHz}$ capacitor $\mathrm{C}_{2}$ conducts, while $\mathrm{C}_{1}$ and $\mathrm{C}_{0}$ still are infinite resistances; so, the equivalent circuit has the shape presented in Figure 2.

Figure 2. Equivalent circuit for the second frequency domain (on the order of $\mathrm{mHz}$ ).

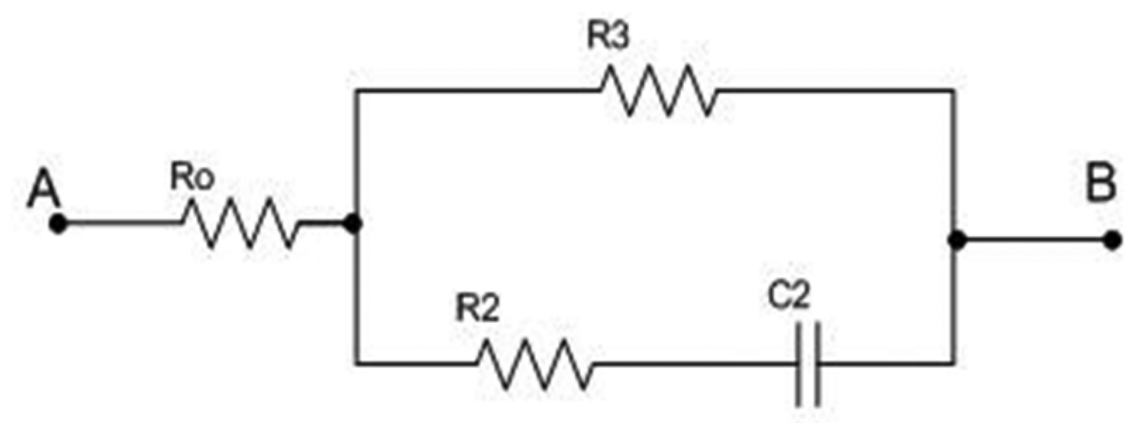


The impedance of the circuit presented in Figure 2 is:

$$
\mathrm{Z}=\frac{\mathrm{S}\left[\left(\mathrm{R}_{1}+\mathrm{R}_{3}\right) \cdot \mathrm{R}_{0} \mathrm{C}_{2}+\mathrm{R}_{2} \mathrm{R}_{3} \mathrm{C}_{2}\right]+\mathrm{R}_{0}+\mathrm{R}_{3}}{\mathrm{SC}_{2}\left(\mathrm{R}_{2}+\mathrm{R}_{3}\right)+1}
$$

From the conditions for the impedance zero and pole, the corner frequencies may be obtained as:

$$
\begin{gathered}
\mathrm{f}_{1}=\frac{1}{2 \pi \cdot\left(\mathrm{R}_{2}+\mathrm{R}_{3}\right) \cdot \mathrm{C}_{2}} \\
\mathrm{f}_{2}=\frac{\mathrm{R}_{0}+\mathrm{R}_{3}}{2 \pi \cdot\left[\left(\mathrm{R}_{2}+\mathrm{R}_{3}\right) \cdot \mathrm{R}_{0} \mathrm{C}_{2}+\mathrm{R}_{2} \mathrm{R}_{3} \mathrm{C}_{2}\right]}
\end{gathered}
$$

At some higher frequencies (in order of dozens $\mathrm{mHz}$ ) $\mathrm{C}_{2}$ becomes short circuit, while $\mathrm{C}_{0}$ and $\mathrm{C}_{1}$ are still in break, so the height of this horizontal region is:

$$
\mathrm{Z}_{2}=\mathrm{R}_{0}+\mathrm{R}_{23} \text { where } \mathrm{R}_{23}=\frac{\mathrm{R}_{2} \mathrm{R}_{3}}{\mathrm{R}_{2}+\mathrm{R}_{3}}
$$

At frequencies on the order of hundreds of $\mathrm{mHz}, \mathrm{C}_{1}$ starts conducting, $\mathrm{C}_{0}$ is still in break, and $\mathrm{C}_{2}$ is a short circuit; the equivalent circuit then has the shape given in Figure 3.

Figure 3. Equivalent circuit for fourth frequency domain (on the order of hundreds of $\mathrm{mHz}$ ).

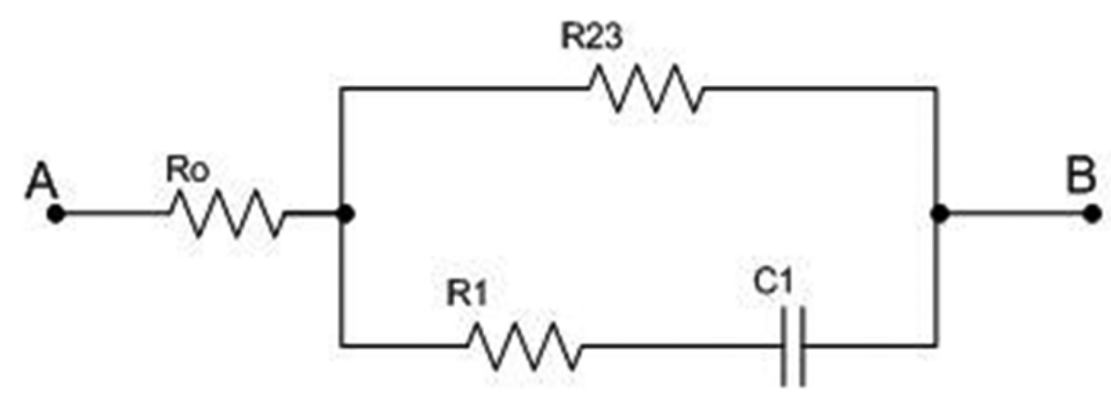

The impedance of the circuit is then:

$$
\mathrm{Z}=\frac{\mathrm{S}\left[\left(\mathrm{R}_{1}+\mathrm{R}_{23}\right) \cdot \mathrm{R}_{0} \mathrm{C}_{1}+\mathrm{R}_{23} \mathrm{R}_{1} \mathrm{C}_{1}\right]+\mathrm{R}_{0}+\mathrm{R}_{23}}{\mathrm{SC}_{1}\left(\mathrm{R}_{1}+\mathrm{R}_{23}\right)+1}
$$

From the previous equation, corner frequencies may be obtained as:

$$
\mathrm{f}_{3}=\frac{1}{2 \pi \cdot\left(\mathrm{R}_{1}+\mathrm{R}_{23}\right) \cdot \mathrm{C}_{1}}
$$

and

$$
\mathrm{f}_{4}=\frac{\mathrm{R}_{0}+\mathrm{R}_{23}}{2 \pi \cdot\left[\left(\mathrm{R}_{1}+\mathrm{R}_{23}\right) \cdot \mathrm{R}_{0} \mathrm{C}_{1}+\mathrm{R}_{23} \mathrm{R}_{1} \mathrm{C}_{1}\right]}
$$

Next horizontal region is obtained at frequencies higher then $1 \mathrm{~Hz}$, when capacitor $\mathrm{C}_{1}$ becomes a short circuit, as well as $\mathrm{C}_{2}$, while $\mathrm{C}_{0}$ still does not conduct; so it can be written: 


$$
\mathrm{Z}_{3}=\mathrm{R}_{0}+\mathrm{R}_{123}
$$

where $R_{123}$ is a parallel connection of $R_{1}, R_{2}$ and $R_{3}$.

At relatively high frequencies (on the order of $\mathrm{kHz}$ ) $\mathrm{C}_{0}$ starts leading, while $\mathrm{C}_{1}$ and $\mathrm{C}_{2}$ are short circuits, so the equivalent circuit becomes as in Figure 4.

Figure 4. Equivalent circuit for sixth frequency domain (on the order of $\mathrm{kHz}$ ).

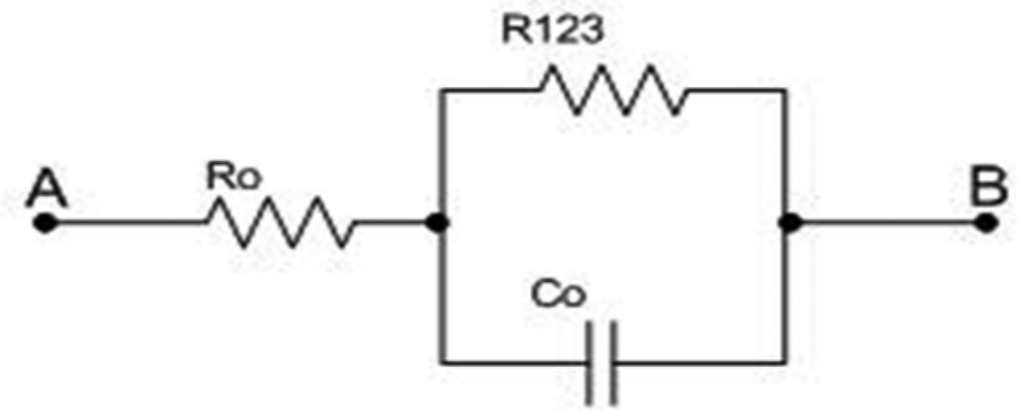

The impedance of such circuit is:

$$
\mathrm{Z}=\frac{\mathrm{SR}_{0} \mathrm{R}_{123} \mathrm{C}_{0}+\mathrm{R}_{0}+\mathrm{R}_{123}}{\mathrm{SR}_{123} \mathrm{C}_{0}+1}
$$

and corner frequencies are:

$$
\begin{gathered}
\mathrm{f}_{5}=\frac{1}{2 \pi \mathrm{R}_{123} \mathrm{C}_{0}} \\
\mathrm{f}_{6}=\frac{\mathrm{R}_{0}+\mathrm{R}_{123}}{2 \pi \mathrm{R}_{0} \mathrm{R}_{123} \mathrm{C}_{0}}
\end{gathered}
$$

At the end, the lowest horizontal part of Bode plot is obtained at highest frequencies (on the order of tens of $\mathrm{kHz}$ ) when $\mathrm{C}_{0}$ is in short circuit, too, so:

$$
\mathrm{Z}_{4}=\mathrm{R}_{0}
$$

The theoretical Bode plot for the whole equivalent circuit given in Figure 1 is presented in Figure 5.

Figure 5. Theoretical Bode plot for adopted equivalent circuit.

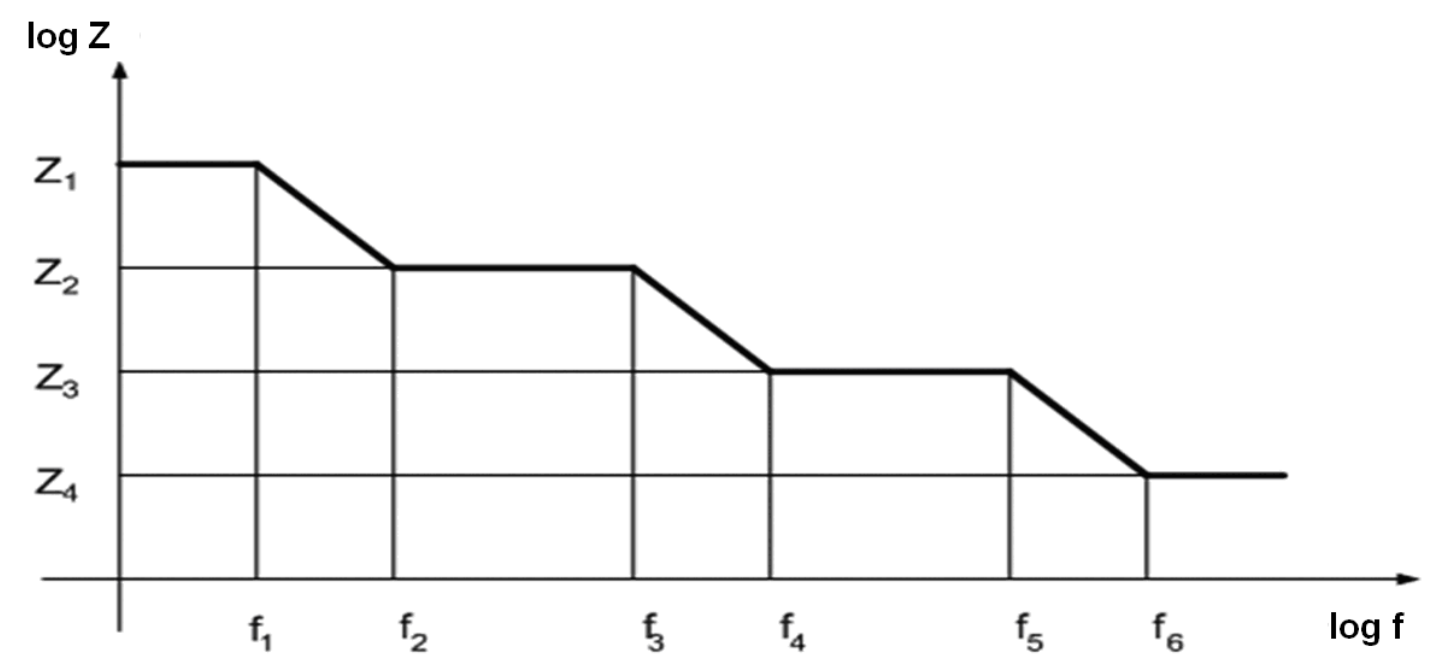




\section{Experimental}

Testing of the system and developed method was done on a physical model of the electrochemical system, constructed of known elements in a defined arrangement as in Figure 1.

The elements that the physical model was made of were: $R_{0}=3 \Omega ; R_{1}=39 \Omega, R_{2}=90 \Omega ; C_{0}=0,12$ $\mu \mathrm{F} ; \mathrm{C}_{1}=30 \mathrm{mF} ; \mathrm{C}_{2}=1,6 \mathrm{~F}$ and $\mathrm{R}_{3}=1 \mathrm{k} \Omega$ (alternatively $\mathrm{R}_{3}=150 \Omega$ ). Experiments were performed using the following parameters: DC level $10 \mathrm{mV}$, AC amplitude $5 \mathrm{mV}$, frequency range $30 \mu \mathrm{Hz}$ up to $1 \mathrm{~Hz}$. The obtained curves are presented in Figures 6 and 7.

Figure 6. Experimentaly obtained Bode plot for the physical model $\left(\mathrm{R}_{3}=1 \mathrm{k} \Omega\right)$.

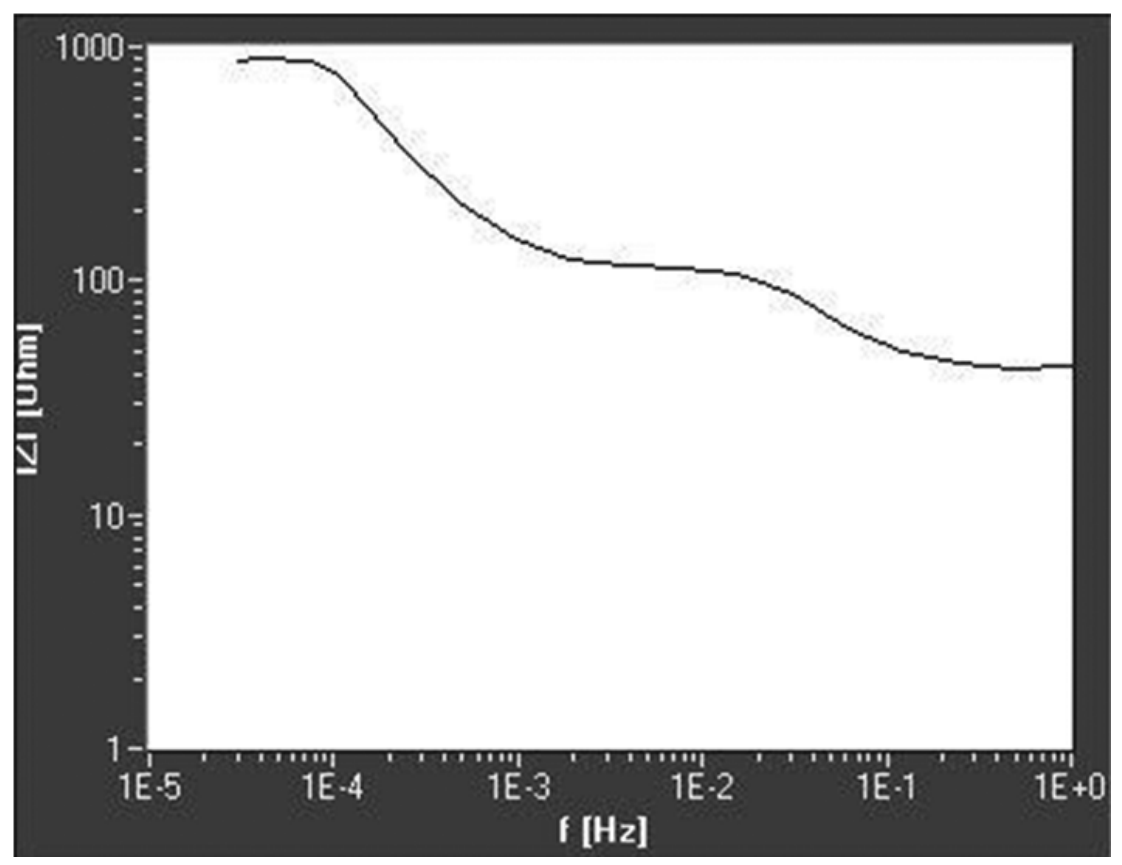

Figure 7. Experimentaly obtained Bode plot for the physical model $\left(\mathrm{R}_{3}=150 \Omega\right)$.

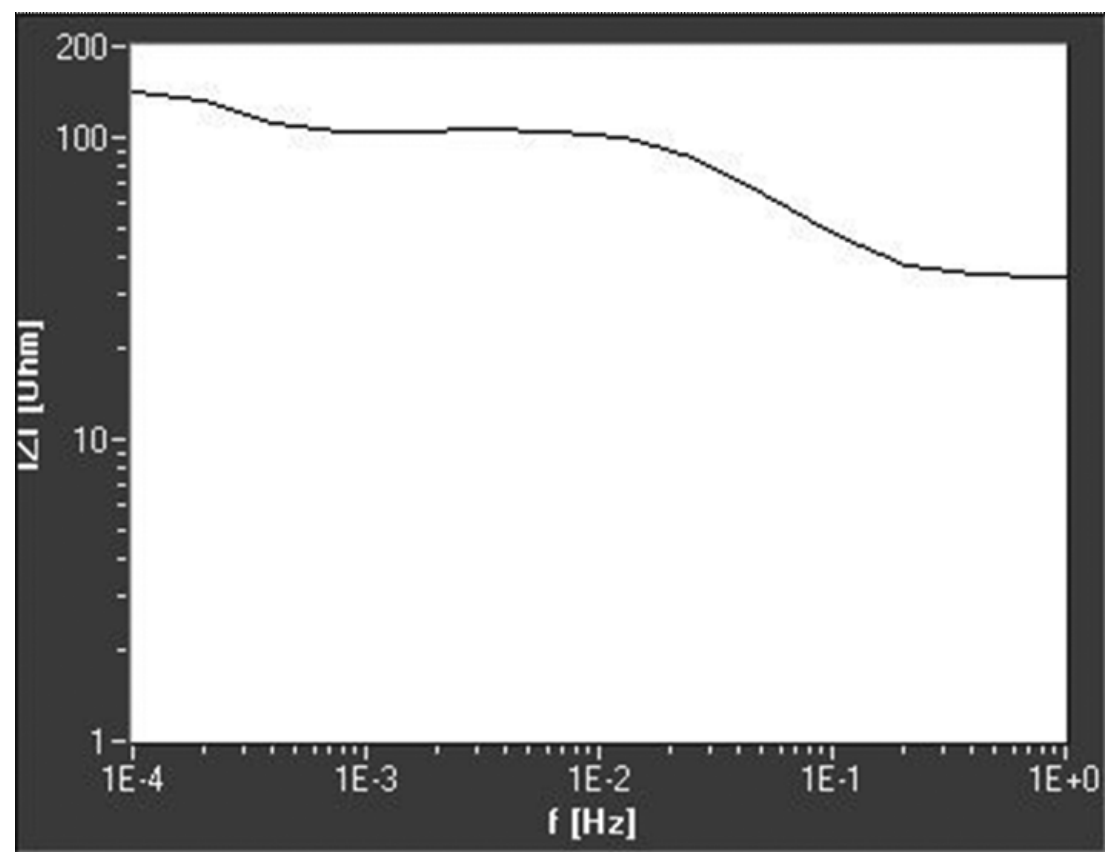


From the experimentally obtained Bode curve, all parameters of the system have been determined by following the next steps:

From the plateau $4, \mathrm{R}_{0}$ is obtained immediately from $\mathrm{R}_{0}=\mathrm{Z}_{4}$;

Horizontal region 1 is equal to $Z_{1}$, and then $R_{3}$ can be calculated from:

$$
\mathrm{R}_{3}=\mathrm{Z}_{1}-\mathrm{R}_{0}
$$

Plateau 2 gives $Z_{2}$, and then applying:

$$
\mathrm{R}_{23}=\mathrm{Z}_{2}-\mathrm{R}_{0} \text { and } \mathrm{R}_{2}=\frac{\mathrm{R}_{23} \mathrm{R}_{3}}{\mathrm{R}_{3}+\mathrm{R}_{23}}
$$

From horizontal part 3 , we get $Z_{3}$ and calculate $R_{123}=Z_{3}-R_{0}$. Then $R_{1}$ can be estimated from:

$$
\mathrm{R}_{1}=\frac{\mathrm{R}_{123} \mathrm{R}_{23}}{\mathrm{R}_{23}+\mathrm{R}_{123}}
$$

From the corner frequency $\mathrm{f}_{1}$, capacitance $\mathrm{C}_{2}$ is calculated from:

$$
\mathrm{C}_{2}=\frac{1}{2 \pi \mathrm{f}_{1} \cdot\left(\mathrm{R}_{2}+\mathrm{R}_{3}\right)}
$$

From the corner frequency $\mathrm{f}_{3}, \mathrm{C}_{1}$ can be calculated as:

$$
\mathrm{C}_{1}=\frac{1}{2 \pi \mathrm{f}_{3} \cdot\left(\mathrm{R}_{1}+\mathrm{R}_{23}\right)}
$$

Finally, from the corner frequency $\mathrm{f}_{5}, \mathrm{C}_{0}$ is estimated as:

$$
\mathrm{C}_{0}=\frac{1}{2 \pi \mathrm{f}_{5} \cdot \mathrm{R}_{123}}
$$

Using the method described above, values of the circuit parameters have been calculated from the plot given in Figure 6. The results are compared with those obtained using the commercial software EqCwin applied to the data from Figure 6 (Table 1).

Table 1. Parameters of the investigated equivalent circuit.

\begin{tabular}{c|c|c|c}
\hline Parameter & Actual value & Measured value & EqCwin value \\
\hline $\mathrm{R}_{1}[\Omega]$ & 39 & 41 & 45 \\
\hline $\mathrm{C}_{1}[\mathrm{~F}]$ & 0.03 & 0.03 & 0.028 \\
\hline $\mathrm{R}_{2}[\Omega]$ & 90 & 93 & 93.4 \\
\hline $\mathrm{C}_{2}[\mathrm{~F}]$ & 1.6 & 1.58 & 1.59 \\
\hline $\mathrm{R}_{3}[\Omega]$ & 1,000 & 992 & 1,003 \\
\hline
\end{tabular}


The plot in Figure 7 gives similar results, except $R_{3}$, that is, in this case, $150 \Omega$. Plots in Figures 6 and 7 do not have the fourth plateau for highest frequencies, so $\mathrm{R}_{0}$ could not be determined from such a curve.

\section{Conclusions}

Table 1 shows a very good agreement between the actual values of the electrical components forming the investigated physical model, the values obtained by the method described in this work and the values obtained using a commercial software product. In that way the method, hardware and software are fully confirmed. It should be emphasized that this method describes the system very well and clearly, but its big disadvantage is that it works with very low frequencies (on the order of $\mu \mathrm{Hz}$ ), that means a need for special equipment (like this described in the present work, or similar) and the experiments have a very long duration. The second problem may be resolved by starting the experiment from a frequency $f_{2}$ (much higher than previously indicated), but in that case $R_{3}$ must be determined by some other method (for example potentiostatic).

\section{References and Notes}

1. Conway, B.E. Electrochemical supercapacitors; Kluwer Academic/Plenum Publishers: New York, NY, USA, 1999; pp. 479-495.

2. Brazill, S.A.; Bender, S.E.; Hebert, N.E.; Cullison, J.K.; Kristensen, E.W.; Kuhr, W.G. Sinusoidal voltammetry: a frequency based electrochemical detection technique. J. Electroanal. Chem. 2002, 531, 119-132.

3. Darowicki, K. Differential analysis of impedance data. Electrochim. Acta 1998, 43, 2281-2285.

4. Arbizzani, C.; Mastragostino, M.; Meneghello, L. Characterization by impedance spectroscopy of a polymer-based supercapacitor. Electrochim. Acta 1995, 40, 2223-2228.

5. Rosvall, S.J.M.; Honeychurch, M.J.; Elton, D.M.; Bond, A.M. A practical approach to applying short time Fourier transform methods in voltammetric investigations. J. Electroanal. Chem. 2001, 515, 8-16.

6. Popkirov, G.S. Fast time-resolved electrochemical impedance spectroscopy for investigations under nonstationary conditions. Electrochim. Acta 1996, 41, 1023-1027.

7. Honda, K.; Rao, T.N.; Tryk, D.A.; Fujishima, A.; Watanabe, M.; Yasui, K.; Masuda, H. Impendance characteristics of the nanoporous honeycomb diamond electrodes for electrical double-layer capacitor applications. J. Electrochem. Soc. 2001, 148, A668-A679.

8. Itagaki, M.; Ono, T.; Watanabe, K. Application of electrochemical impedance spectroscopy to solvent extraction of metallic ions. Electrochim. Acta 1999, 44, 4365-4371.

9. Dekanski, A.; Stevanović, J.; Stevanović, R.; Jovanović, V.M. Glassy carbon electrodes: II. Modification by immersion in $\mathrm{AgNO}_{3}$. Carbon 2001, 39, 1207-1216.

10. Yin, Q.; Kelsall, G.H.; Vaughan, D.J.; Brandon, N.P. Mathematical models for time-dependent impendance of passive electrodes. J. Electrochem. Soc. 2001, 148, A200-A208.

11. Tsamouras, D.; Kobotiatis, L.; Dalas, E.; Sakkopoulos S. An impedance study of the metal sulfide $\mathrm{Cu}_{x} \mathrm{Zn}_{(1-x)} \mathrm{S} /$ electrolyte interface. J. Electroanal. Chem. 1999, 469, 43-47. 
12. Karden, E.; Buller, S.; de Doncker, R.W. A frequency-domain approach to dynamical modeling of electrochemical power sources. Electrochim. Acta 2002, 47, 2347-2356.

13. Avramovic, Z; Antonijevic, M. Corrosion of cold-deformed brass in acid sulphate solution. Corr. Sci. 2004, 46, 2793-2802.

14. Ragoisha, G.A.; Bondarenko, A.S. Potentiodynamic electrochemical impedance spectroscopy Copper underpotential deposition on gold. Electrochem. Commun. 2003, 5, 392-395.

15. Martinez-Ortiz, F. On the use of a real time application interface under Linux in the electrochemistry laboratory - Application to chronopotentiometry. J. Electroanal. Chem. 2005, 574, 239-250.

16. Novickiy, S.P.; Kenzin, V.I.; Voloshin, A.A. Russian Electrochem. 1993, 29, 138-143.

17. Rodriguez, G.; Aromataris, L.; Donolo, M.; Hernandez, J.; Moitre, D. Software for calculation of electric power systems parameters. Comp. Electr. Eng. 2003, 29, 643-651.

18. Stevic, Z.; Andjelkovic, Z.; Antic, D. A New PC and LabVIEW package based system for electrochemical investigations. Sensors 2008, 8, 1819-1831.

19. Stevic, Z.; Rajcic-Vujasinovic, M. Chalcocite as a potential material for supercapacitors. J. Power Sources 2006, 160 1511-1517.

20. Kurek, P.; Thiemann-Handler, S.; Marzantowicz, M.; Foltyn, M. An automated setup for impedance and electrochemical measurements of $\mathrm{NO}_{\mathrm{x}}$ sensors. Ionics 2004, 10, 469-472.

21. Strunz, W. Relaxation voltammetry: A technology for the evaluation of barrier coatings. Electrochem. Appl. 2002, 1/02, 6-10.

22. Hoffmann, J. AC-Impedance Spectroscopy on molten carbonate fuel cells. Electrochem. Appl. 2002, 1/02, 10-12

23. Tan, H.; Su, X.; Wei, W.; Yao, Sh. Robust complex non-linear regression method for the estimation of equivalent circuit parameters of the thickness-shear-mode acoustic wave sensor. Chemometr. Intell. Lab. Sys. 1999, 48 71-80.

24. Borcea, L. Electrical impedance tomography. Inverse Probl. 2002, 18, R99-R136.

25. Nelatury, S.R.; Singh, P. Equivalent circuit parameters of nickel/metal hydride batteries from sparse impedance measurements. J. Power Sources 2004, 132, 309-314.

26. Rajcic-Vujasinovic, M.; Stankovic, Z.; Stevic, Z. The consideration of the electrical circuit analogous to the copper or coppersulfide/electrolyte interfaces based on the time transient analysis. Russ. Electrochem. 1999, 35, 347-354.

(C) 2009 by the authors; licensee Molecular Diversity Preservation International, Basel, Switzerland. This article is an open-access article distributed under the terms and conditions of the Creative Commons Attribution license (http://creativecommons.org/licenses/by/3.0/). 